\title{
Etiology of fever of unknown origin in children.
}

1. MBBS, MCPS, FCPS Senior Registrar Pediatric Medicine The Children's Hospital, Lahore.

2. MBBS, FCPS

Assistant Professor Pediatric Medicine

The Children's Hospital, Lahore.

3. MBBS, FCPS

Assistant Professor Pediatric Medicine

The Children's Hospital, Lahore.

4. MBBS, MCPS, FCPS

Associate Professor Pediatric Medicine

The Children's Hospital, Lahore.

5. MBBS, FCPS

Senior Registrar Pediatric Medicine The Children's Hospital, Lahore.

6. MBBS, FCPS

Assistant Professor Pediatric

Nephrology,

The Children's Hospital, Lahore.

Correspondence Address:

Dr. Aysha Mansoor Lodhi

Department of Pediatric Medicine

The Children's Hospital, Lahore.

drayshaa@hotmail.com

Article received on:

$15 / 08 / 2020$

Accepted for publication:

$02 / 10 / 2020$
Aysha Mansoor Lodhi', Wajiha Rizwan ${ }^{2}$, Mubeen Nazar ${ }^{3}$, Asma Mushtaq $^{4}$, Muhammad Sahir Saud ${ }^{5}$, Shahida Perveen ${ }^{6}$

ABSTRACT... Objectives: To determine the etiology of Fever of Unknown Origin (FUO) in children. Study Design: Prospective Observational study. Setting: Department of Pediatric Medicine, The Children's Hospital, Lahore. Period: August 2019 to January 2020. Material \& Methods: A total of 45 children aged between 01 to 180 months (15 years), having FUO were included. FUO was defined as a temperature of greater than 100.4 ㅇF documented by a health care provider, persisting over a period of three weeks and for which no cause could be identified after at least 8 days of evaluation. All the study information was analyzed by using standard software SPSS 20. The quantitative variables like age and duration of fever before hospital admission were presented as mean and standard deviation. Qualitative variables like sex, antibiotic therapy use before definitive diagnosis and various diagnoses made were presented as frequencies and percentages. Results: The patient's age range was from 01 to 180 months with mean of $80 \pm 45.12$ months and male to female ratio was 2.2:1. Definitive diagnosis was made in $37(82.2 \%)$ patients. Infections were the predominant cause of FUO $(44.4 \%)$ followed by malignancy (24.4\%). Tuberculosis was the most common infection while Acute Lymphoblastic leukemia dominated the malignancy. Systemic lupus erythematosus was the most commonly diagnosed connective tissue disorder. There was a significant association between duration of fever and the ultimate diagnosis $(p=0.01)$. Conclusion: Infectious diseases were the most common cause of FUO followed by malignancy, connective tissue disorders and miscellaneous causes.

Key words: $\quad$ Children, Fever of Unknown Origin, Infections.

Article Citation: Lodhi AM, Rizwan W, Nazar M, Mushtaq A, Saud MS, Perveen S. Etiology of fever of unknown origin in children. Professional Med J 2021; 28(4):552556. https://doi.org/10.29309/TPMJ/2021.28.04.5993

\section{INTRODUCTION:}

Fever of unknown origin (FUO) was originally defined in 1961 by Petersdorf and Beeson ${ }^{1,2}$ as fever of $38.3^{\circ} \mathrm{C}\left(101^{\circ} \mathrm{F}\right)$ recorded on several occasions, persisting over a period of at least three weeks with no diagnosis made despite one week of inpatient investigations.

There is no diagnostic gold standard, so the usual approach requires meticulous fever diary, serial clinical and lab evaluations, vigilance for appearance of new signs and symptoms and targeted investigations. Sometimes clues are found in history and physical examination but not elicited or appreciated, thus, thoroughness and repetition are vitally important. Generally, the pace of evaluation should be guided by the severity of disease rather than anxiety of family or health care provider, so it should be staged leaving invasive investigations for the end. ${ }^{3}$

Investigation should be undertaken based on most likely causes. Blanket investigations are not recommended, as positive or equivocal tests are difficult to interpret in absence of suggestive exposure history or clinical syndrome. ${ }^{4}$ Even with standardized protocols, the cause of FUO cannot be identified in a large number of patients. Some children who look good and whose fever disappear may never have a diagnosis whereas referral to a specialist may be prudent for others. ${ }^{5}$

F.U.O has always been a brainstorming challenge for physicians for not wanting to have a possible morbid or fatal outcome of the undiagnosed condition or for not missing a very treatable 
disease, so patients are often subjected to over the counter labs and therapies including antimicrobial agents and subsequently increasing the burden on both national health system and patients families. ${ }^{6}$

Although the most common category of illnesses presenting with FUO anywhere is infections, with connective tissue disorders and malignancy following, there is wide variation in spectrum of diseases seen within their categories in various regions and countries of world. Whereas it would be illogical to approach FUO on the basis of studies done in geographically far off places because of differences in etiology and genetics, studies done in the nearby also show widely varying results. ${ }^{7}$

Studies on FUO in the pediatric population of Pakistan are virtually nonexistent. Therefore, identifying most common causes of FUO in our region might help us in early diagnosis and timely management of similar cases in the future.

\section{MATERIAL \& METHODS}

A total of 45 children with FUO, having age between 01 to 180 months (15 years) were included in this prospective observational study. It was conducted in the Department of Pediatric Medicine, The Children's Hospital and Institute of Child Health, Lahore from July 2019 to January 2020. FUO was defined as a temperature of greater than 100.4 of documented by a health care provider, persisting over a period of three weeks and for which no cause could be identified after at least 8 days of evaluation.

Sampling technique was non-probability convenient sampling and a proforma was used to enter all the information. Demographic data, duration of fever, history of intake of antibiotic therapy, lab investigations and final diagnosis were noted down. All non-essential medications were stopped and empiric antibiotic therapy was started if patient was sick.

Initial evaluation included detail history, thorough clinical examination and the following laboratory investigations; Complete blood count with peripheral smear, ESR, C-reactive protein, liver function tests, renal function tests, urine analysis, urine and blood culture as well abdominal ultrasound and chest $X$ ray. Further work up was advised according to clues from initial assessment or depending upon patient's clinical course. If the source was identified it was treated, otherwise attention was diverted to categorical workup like cerebrospinal fluid analysis, neuroimaging for central nervous system lesions, Mantoux test and gene expert for Tuberculosis (TB), MP slide for malaria, specific serological tests for infections, Bone marrow biopsy for malignancies and Antinuclear antibody (ANA), Rheumatoid factor (RF) and other autoimmune antibodies for rheumatologic diseases.

All this information was analyzed by using standard software SPSS 20. The quantitative variables like age and duration of fever before hospital admission were presented as mean and standard deviation. Qualitative variables like sex, antibiotic therapy use before definitive diagnosis and various diagnoses made were presented as frequencies and percentages. The Chi-square test was applied and level of significance was considered 0.05 ( $p$ value $<0.05$ ).

\section{RESULTS}

A total of 45 patients were enrolled in this study including 31 (68.9\%) males and 14 (31.1\%) females. The mean age in months was $80 \pm 45.12$ while mean duration of fever at the time of presentation in hospital was $8 \pm 5.58$ weeks. The mean age and duration of fever of patients with FUO caused by different categories of infections, malignancy, connective tissue disorders and miscellaneous cases were shown in (Table-I).

There was history of prior intake of antibiotic therapy before a definitive diagnosis could be made in $34(75.6 \%)$ patients. The total number of diagnosed patients was $37(82.2 \%)$. The most common cause of FUO was infections (44.4\%), followed by malignancy (24.4\%) (Figure-1).

Among infections, TB emerged as the predominant cause. Acute lymphoblastic leukemia (ALL) was the most common malignancy. Systemic 
Lupus Erythematosus (SLE) dominated the Connective Tissue Disorders while 3 cases from miscellaneous group were of Hemophagocytic Lymphohistiocytosis (HLH). (Table II). A significant association was found between duration of fever and the ultimate diagnosis $(p=0.01)$.

\begin{tabular}{|c|c|c|}
\hline & $\begin{array}{c}\text { Age } \\
\text { Mean }=80 \pm 45.12\end{array}$ & $\begin{array}{l}\text { Duration of Fever } \\
\text { Mean }=8 \pm 5.58\end{array}$ \\
\hline Infections & $66.25 \pm 44.27$ & $6.85 \pm 4.91$ \\
\hline Malignancy & $86.82 \pm 44.37$ & $8.36 \pm 5.71$ \\
\hline $\begin{array}{l}\text { Connective } \\
\text { tissue disorders }\end{array}$ & $112 \pm 30.2$ & $11.33 \pm 11.02$ \\
\hline Miscellaneous & $128 \pm 13.86$ & $10.67 \pm 2.31$ \\
\hline $\begin{array}{l}\text { Undiagnosed } \\
\text { cases }\end{array}$ & $63.14 \pm 59.79$ & $8.88 \pm 5.64$ \\
\hline
\end{tabular}

- Infection $\square$ Malignancy $\square$ Connective tissue Miscellaneous

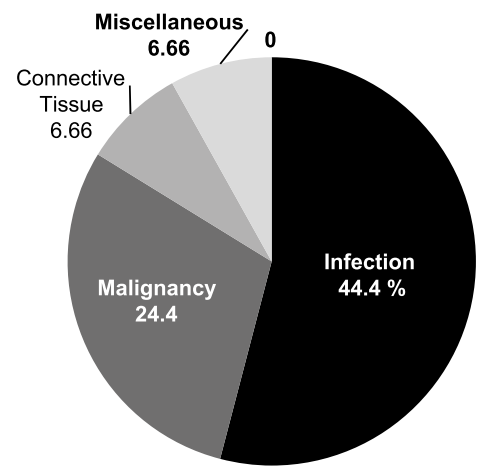

Figure-1. Etiology of FUO in children

\begin{tabular}{|c|c|c|c|}
\hline & & $\mathbf{N}$ & $\%$ \\
\hline \multirow[t]{5}{*}{1} & Diagnosed cases & 37 & 82.2 \\
\hline & $\begin{array}{l}\text { Infection } \\
\text {-TB } \\
\text {-Typhoid } \\
\text {-Malaria } \\
\text {-Leishmaniasis }\end{array}$ & $\begin{array}{l}20 \\
10 \\
05 \\
03 \\
02\end{array}$ & 44.4 \\
\hline & $\begin{array}{l}\text { Malignancy } \\
\text {-ALL } \\
\text {-Lymphoma }\end{array}$ & $\begin{array}{l}11 \\
08 \\
03\end{array}$ & 24.4 \\
\hline & $\begin{array}{l}\text { Connective tissue disorders } \\
\text {-SLE } \\
\text {-JIA }\end{array}$ & $\begin{array}{l}03 \\
02 \\
01\end{array}$ & 6.66 \\
\hline & $\begin{array}{l}\text { Miscellaneous } \\
\text {-HLH }\end{array}$ & 03 & 6.66 \\
\hline 2 & Undiagnosed cases & 08 & 17.8 \\
\hline \multicolumn{4}{|c|}{$\begin{array}{l}\text { Table-Il. Category wise etiology of FUO in Children } \\
\qquad N=45\end{array}$} \\
\hline
\end{tabular}

Professional Med J 2021;28(4):552-556.
$\mathrm{ALL}=$ Acute Lymphoblastic Leukemia, SLE $=$ Systemic Lupus Erythematosus, JIA=Juvenile Idiopathic Arthritis, $\mathrm{HLH}=$ Hemophagocytic Lymphohistiocytosis

\section{DISCUSSION}

Fever in children is one of the major causes of distress for parents and if it gets prolonged, it usually becomes worrisome for attending clinicians that might lead to unnecessary investigation and prescription of broad-spectrum antibiotics.

The mean age of patients in our study was 80 months and the patients presenting with infections and undiagnosed cases were younger as compared to other diagnostic categories. This fact is documented in other studies as well. ${ }^{8}$ The mean duration of fever was 8 weeks and the patients with infections had earlier presentation as compared to other causes of FUO.

Majority of patients in our study (44.4\%) presented with infections which still dominate the list of FUO in children in both developing and underdeveloped countries. In a study conducted in India by Dayal et $\mathrm{al}^{9}$, fifty-three patients out of 100 had infections as causative agents. Another study by Joshi $\mathrm{N}^{10}$ documented similar findings. A study in a tertiary care Egyptian Hospital by Hassan $\mathrm{RH}$ showed infections to be the most common cause of FUO in 46 cases out of total 127 patients. ${ }^{11}$ In studies done in Turkey, Italy and Taiwan $8,12,13,14,15$, similar trends were noted. Chien $\mathrm{YL}$ et al in Taiwan reported infections to be the dominant cause, followed by malignancy, miscellaneous causes and collagen vascular disease. ${ }^{15} \mathrm{~TB}$ was the most frequent cause of FUO in our patients followed by Typhoid fever. Studies from India and Turkey share similar results. ${ }^{8,9,10,12}$

The diagnosis of common diseases like Typhoid was delayed possibly because either blood cultures were not done at right time or incomplete antibiotic therapy temporarily suppressed the infection only to resurface again. In our study 34 patients $(75.6 \%)$ had at least one antibiotic course before referral to hospital which particularly renders the diagnosis of infectious diseases 
difficult as isolation and growth of microorganisms in cultures is decreased. For the same reasons multi drug resistant Salmonella has emerged as a grave issue in Pakistan. ${ }^{16}$ There is an urgent need to discourage irrational use of antibiotics to prevent mortality and morbidity associated with increasing resistance to antibiotics in pathogens. For diagnosis of Typhoid keeping high index of suspicion and repeated cultures to isolate Salmonella helped in reaching the diagnosis. The two patients of leishmaniasis had massive slpenomegaly and bone marrow biopsy demonstrated Leishmania Donovani.

Second most common cause of FUO in our study was malignancy $(n=11,24.4 \%)$. ALL was the most common malignancy followed by Lymphoma. Since ours is a tertiary care hospital, imaging techniques like CT Scan, MRI, Bone Marrow Aspiration and Biopsy, Lymph Node Biopsy and Histopathology were readily available and facilitated diagnosis.

Connective tissue disorders $(n=3,6.6 \%)$ were the third most frequent cause of FUO. In miscellaneous group three patients were diagnosed with Hemophagocytic Lymphohistiocytosis (HLH). Atypical presentations are quite common as well as FUO, which explains the delay in diagnosis. ${ }^{17}$

Undiagnosed patients constituted $17.8 \%$ of the total cases. None of these patients were febrile at the time of discharge and stayed well afterwards as monitored by follow up visits. The most likely cause was assumed to be some viral infections which presented atypically and for which lab diagnostics were not available in our setup. We do believe that with availability of viral serology and culture in future the burden of undiagnosed cases would decrease.

We found a significant association between duration of fever and the ultimate diagnosis $(p=$ 0.01 ). Longer the duration of fever, more rapid was the final diagnosis, made within one week of hospital admission presumably because all the signs and symptoms of disease were fully apparent by then. Though it is a well-established fact that incomplete or irrational antibiotic therapy would suppress the infections and alter the results of blood cultures as reported by multiple studies ${ }^{18}$ the association of prior antibiotic therapy with duration of fever and cases which couldn't be diagnosed was found to be insignificant $(p=$ 0.81).

Some of the limitations of our study were lack and reliability of some lab tests and the fact that this data was collected from a tertiary care center where there is referral of more complicated cases and incidence of infections and malignancies may be higher so results may not be able to reflect the current epidemiology of FUO in Pakistan; nonetheless this study is the first one on FUO in children in our country and brings some important insights into this entity.

\section{CONCLUSION}

Infections are the leading cause of FUO in children followed by malignancy, connective tissue disorders and miscellaneous cases. TB is the predominant cause among infections. ALL is the most common form of malignancy while SLE dominated among the cases of connective tissue disorders.

\section{Copyright $\odot 02$ Oct, 2020.}

\section{REFERENCES}

1. Petersdorf RG, Beeson PB. Fever of unexplained origin: Report of $\mathbf{1 0 0}$ cases. Medicine (Baltimore) 1961; 40: 1-30.

2. Petersdorf RG. Fever of unknown origin: an old friend revisited. Arch Intern. Med. 1992: 15221-22.

3. Chusid MJ. Fever of unknown origin in childhood. Pediatr clin N, Am.2017. 64; 205-230.

4. Fernandez C, Beeching NJ. Pyrexia of unknown origin. Clin Med. 2018; 18: 170-4.

5. Statler V.A, Marshall GS. Evaluation of prolonged and recurrent unexplained fevers. Pediatr Annals.2018; 47(9); e347-e353.

6. Szymanski A.M, Clifford H, Ronis T. Fever of unknown origin; a retrospective review of Pediatric patients from an urban tertiary care center in Washington, DC. World J Pediatr. 2019; 1-8. 
7. Cho CY, Li CC, Lee ML, Hsn CL, Chen CJ, Change LY. Clinical analysis of fever of unkown origin in children: A 10-year experience in a Northern Taiwan Medical center. J Microbiol Immunol Infect. 2017; 50 (1): 40-45.

8. Tezer H, Cyhan M, Kara A, Cengiz B, Devrim I, Secmeer G. Fever of unkown origin in children: the experience of one centre in Turkey. Turk. J. Pediatr. 2012; 54: 583589.

9. Dayal R, Agarwal D. Fever in children and fever of unknown origin. Indian J Pediatr.2016; 83:38-43.

10. Joshi N, Rageshwari K, Dubey A.P, Singh T, Kaur R. Clinical spectrum of fever of unknown origin among Indian children. J Trop. Pediatr. 2008; 28(4): 261266.

11. Hassan RH, Fouda AE, Kandil SM. Fever of unkown origin in children; A 6-year experience in a tertiary pediatric Egyptian hospital. Int $\mathrm{J}$ health Sci (Qarum) 2014; 8(1); 13-19.

12. Gundesoglu OO, Kocabas E, Ilhan E, Aksary N, Alabaz $D$, Karagim BS. Fever of unkown origin. Evaluation of 30 pediatric patients. Cukurova Med J. 2019; 44: 215220.
13. Rigante D, Esposito S. A Road map for fever of unknown origin in children. Int $\mathrm{J} \mathrm{ImmunopatholPharmacol.} \mathrm{2013;}$ 26(2): 315-26.

14. Kim YS, Kim KR, Kang JM, King JM, Kim YJ. Etiology and clinical characteristics of fever of unknown origin in children: A 15-year experience in a single centre. Korean J Pediatr. 2017; 60: 77-85.

15. Chien YL, Hunang FL, Huang CM, Chen PY. Clinical approach to fever of unknown origin in children. $J$ Microbiolimmunol infect. 2017: 50(6); 893-898.

16. Rasheed MK, Hassan SS, Babar Z, Ahmed SI. Extensively drug resistant typhoid fever in Pakistan. Lancet infects Dis. 2019; 19(3): P242-243.

17. Chouchan S, Chouchane C.H, Ben Menem CH, Selet $B$, Hammamis $S$, Nouri $S$ et al. Prolonged fever in children. Retrospective study of 67 cases. Arch Pediatr. 2004 (11): 1319-1325.

18. Landge $A A$, Singhal T. Etiology of fever of unknown origin in children from Mumbai, India. Indian pediatrics. 2018; 55(1):71-2.

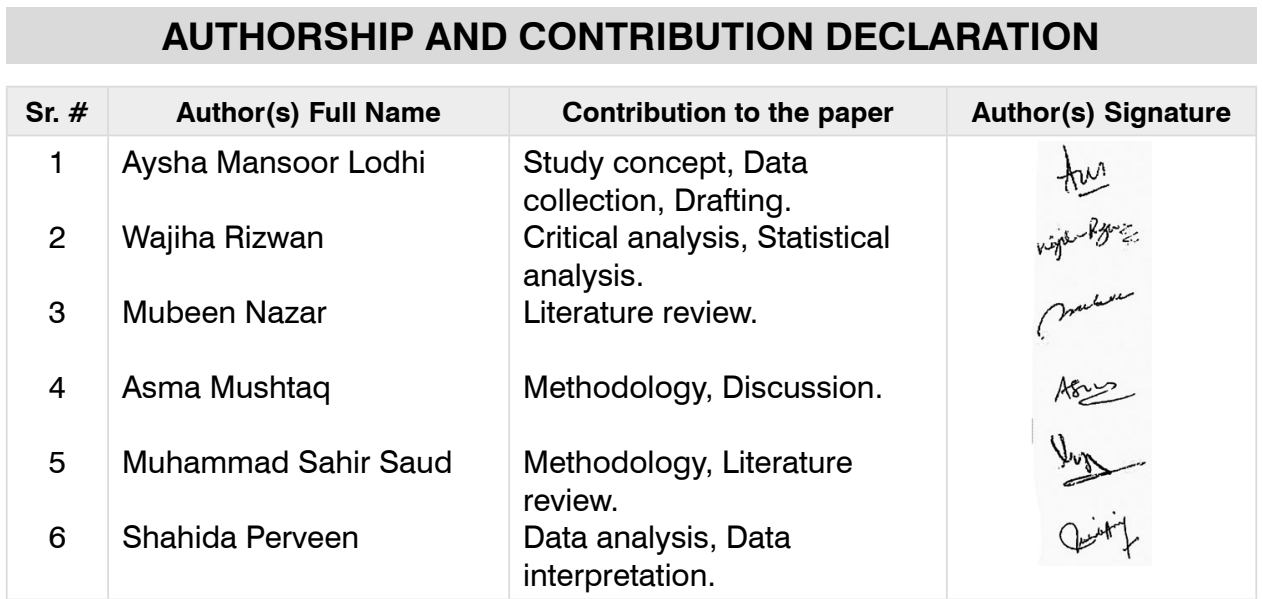

